\title{
FUNCTIONAL OUTCOME OF DISPLACED MIDCLAVICULAR FRACTURE FIXATION UTILISING PLATE OSTEOSYNTHESIS IN A TERTIARY CARE CENTRE OF TRIPURA
}

\author{
Bhupes Sil1, Sankar Debroy², Sandeep Kumar Deep ${ }^{3}$
}

${ }_{1}^{1}$ Assistant Professor, Department of Orthopaedics, Agartala Government Medical College and GB Pant Hospital, Agartala, Tripura, India.

${ }^{2}$ Assistant Professor, Department of Orthopaedics, Agartala Government Medical College and GB Pant Hospital, Agartala, Tripura, India.

${ }^{3}$ Postgraduate Student, Department of Orthopaedics, Agartala Government Medical College and GB Pant Hospital, Agartala, Tripura, India.

\section{BACKGROUND}

ABSTRACT

Clavicular fractures are common and frequent, and they account for 5-10\% of all fractures with midshaft fractures comprising 80 $85 \%$. Conservative methods were the mainstay of treatment previously, but recent trends indicate that surgical fixation in cases with displaced fractures gives better functional results, decreased rate of non-union and early recovery.

\section{MATERIALS AND METHODS}

A prospective observational study was conducted in a tertiary care centre of Tripura between June 2016 and Nov 2017, where 27 cases of displaced midclavicular fractures were treated with open reduction and internal fixation with 2 different types of plates. Out of 27 cases, eight were fixed with reconstruction plates and 19 with anatomical locking compression plate. Follow-up was done at regular interval with a minimal follow-up of 6 months and maximum upto 16 months. Functional outcome was evaluated using Constant-Murley score.

\section{RESULTS}

Majority (81\%) of the cases were males belonging to 20 - 30 years' age group. 70\% of the cases were under Robinson type 2B1 classification and rest were in 2B2. 25 (93\%) fracture cases united within 12 weeks with a mean of 9.4 weeks, 1 case went into non-union with implant failure and 1 case into delayed union. In the minor post-operative complications, 3 cases complained of hypertrophic scar, 2 cases of incisional numbness and no case of wound infection was seen. Majority (81.4\%) of the cases had excellent functional score, while only $3.7 \%$ cases showed poor score.

\section{CONCLUSION}

Surgical fixation in acute displaced midshaft clavicle fractures results in early union with decreased complications, giving excellent functional outcome and early return to work.

\section{KEY WORDS}

LCP- Locking Compression Plate.

HOW TO CITE THIS ARTICLE: Sil B, Debroy S, Deep SK. Functional outcome of displaced midclavicular fracture fixation utilising plate osteosynthesis in a tertiary care centre of Tripura. J. Evolution Med. Dent. Sci. 2018;7(45):4839-4843, DOI: $10.14260 /$ jemds/2018/1078

\section{BACKGROUND}

Clavicle fractures are commonly found in young age groups accounting for 5 to $10 \%$ of all fractures ${ }^{1}$ and represents 35 $44 \%$ of all shoulder girdle injuries. $2-5 \quad 80-85 \%$ of these fractures occur in the midshaft, $621-28 \%$ in lateral end and 2$3 \%$ in medial end.7 General consensus was that majority of clavicle fractures heal well without operative intervention. Till now neurovascular compromise and open fractures were the only indications for surgical management. ${ }^{8}$ But recent studies showed that an exception should be made for the subgroup of patients called as Displaced Midshaft Clavicle

'Financial or Other Competing Interest': None.

Submission 24-09-2018, Peer Review 17-10-2018,

Acceptance 25-10-2018, Published 05-11-2018.

Corresponding Author:

Dr. Sandeep Kumar Deep,

Room No. 77, PG Boys Hostel,

AGMC and GBP Hospital,

Agartala-799006,

Tripura, India.

E-mail: dr.sandeep2309@gmail.com

DOI: $10.14260 /$ jemds/2018/1078

Fractures (DMCF), as the prevalence of mal-union and nonunion is higher in this subgroup when treated conservatively. A reduced rate of non-union after treatment with plate fixation $(2.2 \%)$ compared with non-operative care $(15.1 \%)$ has been found that shows a clear superiority of operative fixation against conservative management. ${ }^{9}$ In addition, due to fracture fixation patients are able to return to daily activities early following surgery, had better functional outcome and better cosmetic appearance than the conservatively managed counterparts. ${ }^{10}$ There are various methods for treating clavicle midshaft fractures, such as intramedullary $\mathrm{K}$ wires or Steinmann pin fixation or plate fixation. Open reduction and internal fixation with plating provides rigid fixation, early functional recovery and low rates of non-union and mal-union. ${ }^{11}$ As it helps in obtaining firm anatomical reduction in severely displaced or comminuted fracture, it is implant of choice in these categories of patients. There are various plates available and amongst them anatomical locking compression plate and locking reconstruction plate, which can be bent to the $S$ shaped curvature of the clavicle are the most preferred.12 
The purpose of this study was to evaluate the functional outcome in displaced midshaft clavicular fractures treated by plate osteosynthesis.

\section{MATERIALS AND METHODS}

A prospective observational study was conducted between June 2016 and November 2017 in the Orthopaedics Department at Agartala Government Medical College and GB Pant Hospital. All patients presented with clavicle fractures were included in the study who were having closed displaced midshaft fracture, age $>18$ years, shortening $>2 \mathrm{~cm}$ and segmental fracture. Patients presented with open fracture, pathological fracture, fracture in medial or lateral end or who were declared unfit for surgery were excluded from the study. Examination of the injury site was done thoroughly and recorded in the proforma. All routine investigations were done pre-operatively. After pre-anaesthetic fitness, consent was taken for surgery. Open reduction and internal fixation of fracture utilising plate osteosynthesis was done with the help of IITV where needed. Rehabilitation of the affected extremity was done $5^{\text {th }}$ post-op day onwards. After 2 weeks, gravity assisted exercises were allowed and abduction was allowed upto 90 degrees. After 6 weeks, active range of motion in all planes were allowed. For the initial 2 months follow-up was done fortnightly, then monthly for the next 4 months. Maximum follow-up period was 16 months and minimum 6 months where local examination of the affected clavicle for tenderness, instability deformity, union and shoulder movements were assessed. X-rays were taken at each followup visits to know about progress of fracture union and implant position. Patients were followed up till radiological union, modified Constant and Murley score ${ }^{13}$ was used to assess the functional outcome. Final follow-up was done at the end of 6 months. Functional outcome evaluation was done using Constant and Murley scoring, ${ }^{13}$ which has subjective and objective parameters.

Individual data collections were kept anonymous and strict confidentiality was maintained. Descriptive statistics were expressed in frequencies and percentages. The study was conducted after obtaining permission from Institutional Ethics Committee of Agartala Govt. Medical College.

Scoring was done based on subjective and objective parameters according to Constant-Murley Score

\begin{tabular}{|c|}
\hline Pain (Maximum= 15 Points) \\
No pain- 15 \\
Mild- 10 \\
Moderate- 5 \\
Severe- 0 \\
\hline Activities of Daily Living (Maximum= 20 Points) \\
Ability to perform full work- 04 \\
Ability to perform Leisure activities/ Sports- 04 \\
Unaffected sleep- 02 \\
Level at which work can be done: Upto Waist- 02 \\
Upto Xiphoid- 04 \\
Upto Neck- 06 \\
Upto Head- 08 \\
Above head- 10 \\
\hline Table 1. Subjective Assessment of Participants
\end{tabular}

\begin{tabular}{|c|c|c|c|c|}
\hline \multicolumn{4}{|c|}{$\begin{array}{c}\text { Range of Motion } \\
\text { (Maximum }=40 \text { Points) }\end{array}$} & $\begin{array}{l}\text { Strength of } \\
\text { Abduction } \\
\text { (Maximum= }\end{array}$ \\
\hline $\begin{array}{c}\text { Active } \\
\text { flexion } \\
\text { without } \\
\text { pain: } \\
\text { 0-300: } 0 \\
31-600: 2 \\
61-900: 4 \\
91-1200: 6 \\
121-1500: \\
8 \\
>1510: 10\end{array}$ & \begin{tabular}{|c} 
Functional \\
external \\
rotation: \\
Hand \\
behind \\
head with \\
elbow \\
forwards- \\
2 \\
Hand \\
behind \\
head with \\
elbow \\
backwards- \\
4 \\
Hand above \\
head with \\
elbow \\
forwards- \\
6 \\
Hand above \\
head with \\
elbow \\
backwards- \\
8 \\
Full \\
elevation \\
from on top \\
of head- 10
\end{tabular} & $\begin{array}{c}\text { 0-300: } 0 \\
\text { 31-600: } \\
61-900: 4 \\
91-1200: 6 \\
121-1500: \\
8 \\
>1510: 10\end{array}$ & \begin{tabular}{|} 
With \\
dorsum of \\
hand on \\
back \\
reaches- \\
Ipsilateral \\
buttock: 2 \\
S1 spinous \\
process: 4 \\
L3 spinous \\
process: 6 \\
T12 \\
spinous \\
process: 8 \\
T7 spinous \\
process: \\
10
\end{tabular} & \begin{tabular}{|c|} 
A normal \\
shoulder \\
resists 25 \\
pounds without \\
difficulty. \\
The score given \\
for normal \\
power is 25 \\
points with \\
proportionately \\
less for less \\
power. \\
\end{tabular} \\
\hline & le 2. Objecti & & of 1 & ticipants \\
\hline
\end{tabular}

Final Score evaluation according to Constant-Murley Score

\begin{tabular}{|c|c|}
\hline Score & Grading \\
\hline $91-100$ & Excellent \\
\hline $81-89$ & Good \\
\hline $71-80$ & Satisfactory \\
\hline $61-70$ & Adequate \\
\hline$<60$ & Poor \\
\hline
\end{tabular}

\section{RESULTS}

27 patients fulfilling the inclusion criteria were included in the study. No patient was lost for follow-up.

\begin{tabular}{|c|c|c|}
\hline Characteristics & $\begin{array}{c}\text { Number of } \\
\text { Patients (n) }\end{array}$ & Percentage (\%) \\
\hline Sex & 22 & 81.5 \\
\hline Male & 5 & 18.5 \\
\hline Female & Age Groups \\
\hline \multicolumn{3}{|c|}{} \\
\hline < 20 years & 3 & 11.2 \\
\hline $20-30$ years & 22 & 81.4 \\
\hline $31-40$ years & 1 & 3.7 \\
\hline 41-50 years & 1 & 3.7 \\
\hline \multicolumn{2}{|c|}{ Table I. Age and Sex distribution of the Patients } \\
\hline
\end{tabular}

Majority (81\%) of the patients belonged to 20 - 30 years of age group with mean age of 25 years $(+/-9)$. 


\begin{tabular}{|c|c|c|}
\hline $\begin{array}{c}\text { Robinson Classification } \\
\text { Type }\end{array}$ & $\begin{array}{c}\text { Number of Patients } \\
\text { (n) }\end{array}$ & (\%) \\
\hline 2B1 & 19 & 70.3 \\
\hline 2B2 & 8 & 29.7 \\
\hline \multicolumn{2}{|c|}{ Table II. Type of Fracture as per Robinson Classification } \\
\hline
\end{tabular}

$70 \%$ of the patients had type 2 middle-third fracture B1 (Displaced with single or single butterfly fragment), while $30 \%$ patients had type 2B2 (Displaced with comminuted or segmental). Twenty-one clavicles were fractured on the right side and six on the left side. The mechanism of injury was road traffic accident in 18 cases, fall in 5 cases and 4 while playing sports. There were three patients with associated lesions, one with fracture of both bone leg, second had fracture of both bone forearm and the third had a fracture of the shaft of femur.

\begin{tabular}{|c|c|c|}
\hline Characteristics & Number of Patients (n) & $(\%)$ \\
\hline \multicolumn{3}{|l|}{$\begin{array}{l}\text { Injury to Surgery } \\
\text { Interval }\end{array}$} \\
\hline$<1$ week & 4 & 14.8 \\
\hline 1-2 weeks & 20 & 74.0 \\
\hline$>2$ weeks & 3 & 11.2 \\
\hline \multicolumn{3}{|c|}{ Type of Plate Used } \\
\hline Reconstruction plate & 8 & 26.6 \\
\hline $\begin{array}{l}\text { Anatomical locking } \\
\text { compression plate }\end{array}$ & 19 & 70.4 \\
\hline \multicolumn{3}{|c|}{ Fracture Time to Unite } \\
\hline 6-8 weeks & 1 & 3.8 \\
\hline 8-10 weeks & 19 & 70.37 \\
\hline 10-12 weeks & 6 & 22.22 \\
\hline$>12$ weeks & 1 & 3.8 \\
\hline \multicolumn{3}{|c|}{ Type of Post-Operative Complication } \\
\hline Non-union & 1 & 3.8 \\
\hline Delayed union & 1 & 3.8 \\
\hline Hypertrophic scar & 3 & 11.1 \\
\hline Incisional numbness & 2 & 7.3 \\
\hline \multicolumn{3}{|c|}{ Table III. Treatment Profile of the Participants } \\
\hline
\end{tabular}

Majority (74\%) patients got treated within 2 weeks of the stay in hospital with mean operation deadline of 14 days. Mostly anatomical locking compression plate was used to provide stability to the displaced clavicle. Majority of the patient's clavicle got united within 8 - 10 weeks with an average time of 9.4 weeks. Approximately, $75 \%$ of the patients did not suffer any of the post-operative complications mentioned, while $11 \%$ complained of hypertrophic scar, collectively $7.6 \%$ patients complained of non-union due to implant failure and delayed union and there was no single case of wound infection seen.

\begin{tabular}{|c|c|c|}
\hline $\begin{array}{l}\text { Functional } \\
\text { Outcome }\end{array}$ & $\begin{array}{c}\text { Number of } \\
\text { Patients (n) }\end{array}$ & Percentage (\%) \\
\hline Excellent & 22 & 81.48 \\
\hline Good & 4 & 14.81 \\
\hline Satisfactory & 0 & 0 \\
\hline Adequate & 0 & 0 \\
\hline Poor & 1 & 3.8 \\
\hline
\end{tabular}

Excellent functional outcome was found in $81.4 \%$ cases with 1 patient reporting poor functional outcome due to implant failure. Mean Constant-Murley score was 92 with a range of 54 to 100 .

\begin{tabular}{|c|c|c|c|c|c|}
\hline & \multicolumn{5}{|c|}{ Functional Outcome } \\
\hline $\begin{array}{c}\text { Age } \\
\text { Group } \\
\text { (Years) }\end{array}$ & Excellent & Good & Satisfactory & Adequate & Poor \\
\hline$<20$ & 3 & 0 & 0 & 0 & 0 \\
\hline $21-30$ & 18 & 3 & 0 & 0 & 1 \\
\hline $31-40$ & 0 & 1 & 0 & 0 & 0 \\
\hline $41-50$ & 1 & 0 & 0 & 0 & 0 \\
\hline
\end{tabular}

Majority of the excellent functional outcome was seen in age group of 21 - 30 years. Only 1 case of poor functional outcome was noted in the same age group.

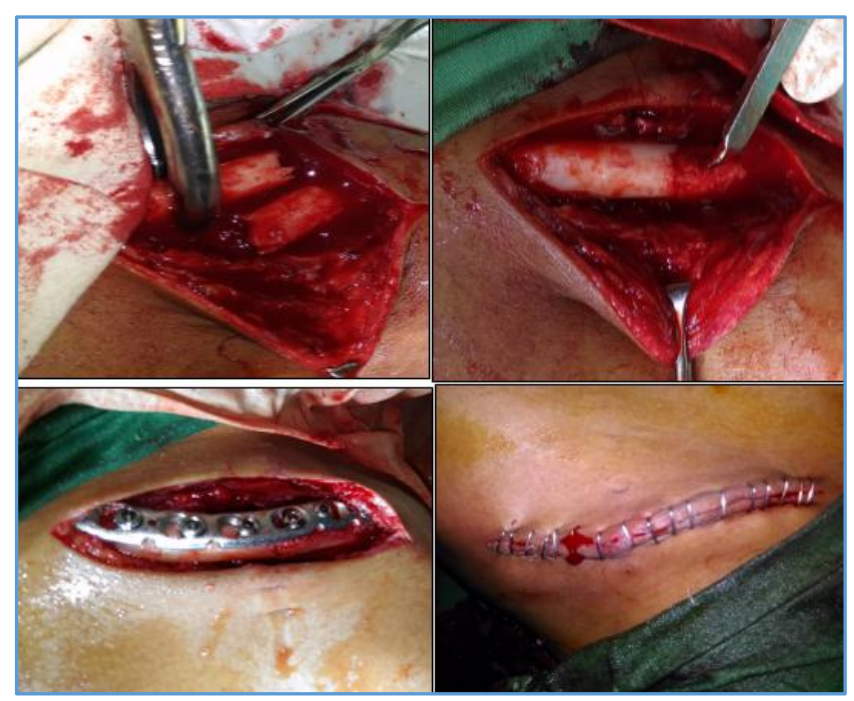

Figure 1. Intraoperative Pictures
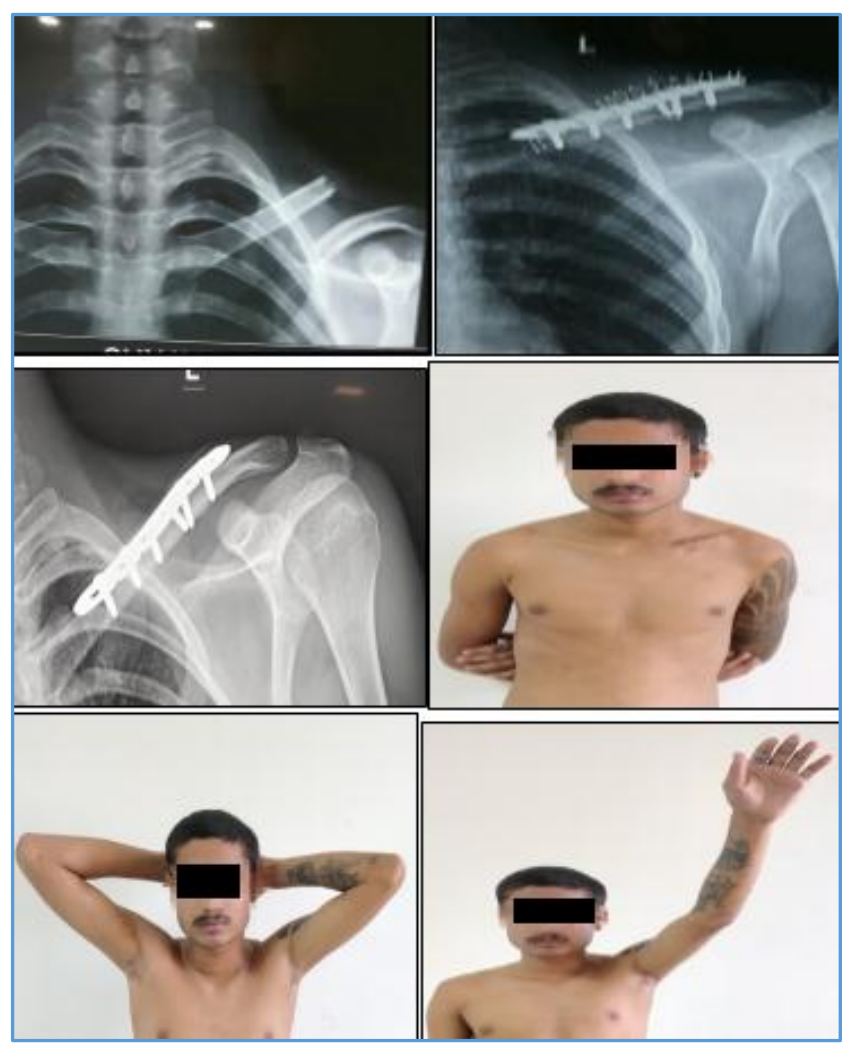

Figure (2) a. Preoperative Radiograph of a Midshaft Fracture of Left Clavicle; b. Post-operative Image after Plate Fixation; c. Image after Fracture Union; d. e. f. Clinical Image showing Good Functional Outcome 


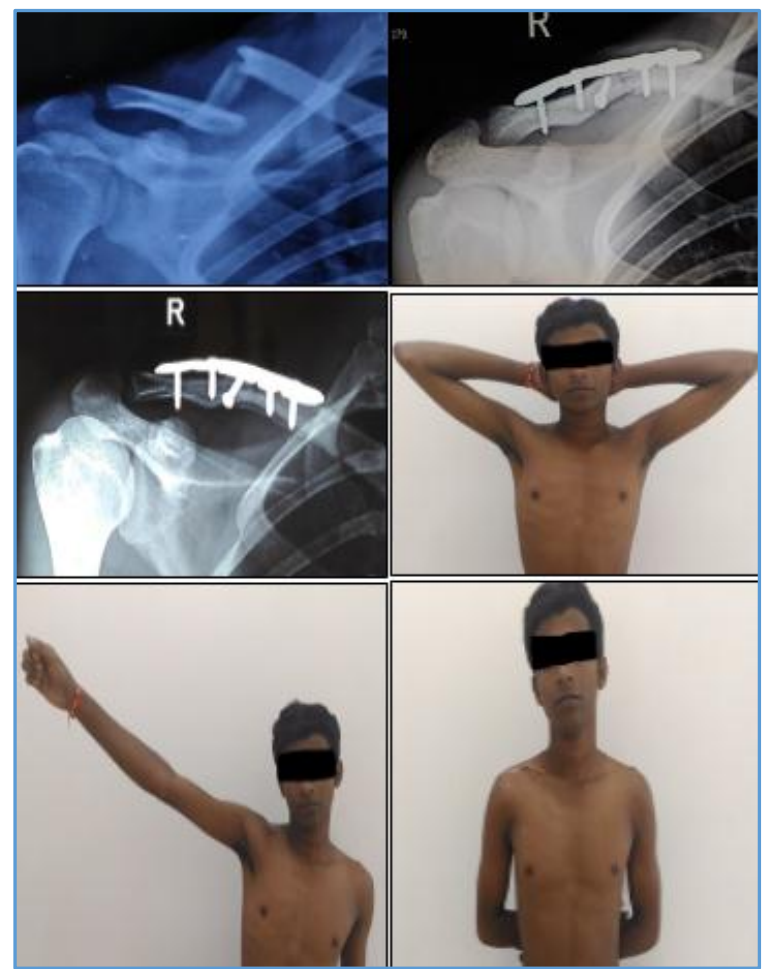

Figure (3) a. Preoperative Radiograph of a Comminuted Midshaft Fracture of Right Clavicle; b. Immediate Postoperative Radiograph showing Fracture Fixation by Plate and Interfragmentary Screw; c. Radiograph after Fracture Union; $d, e, f$. Clinical Image showing Good Range of Motion

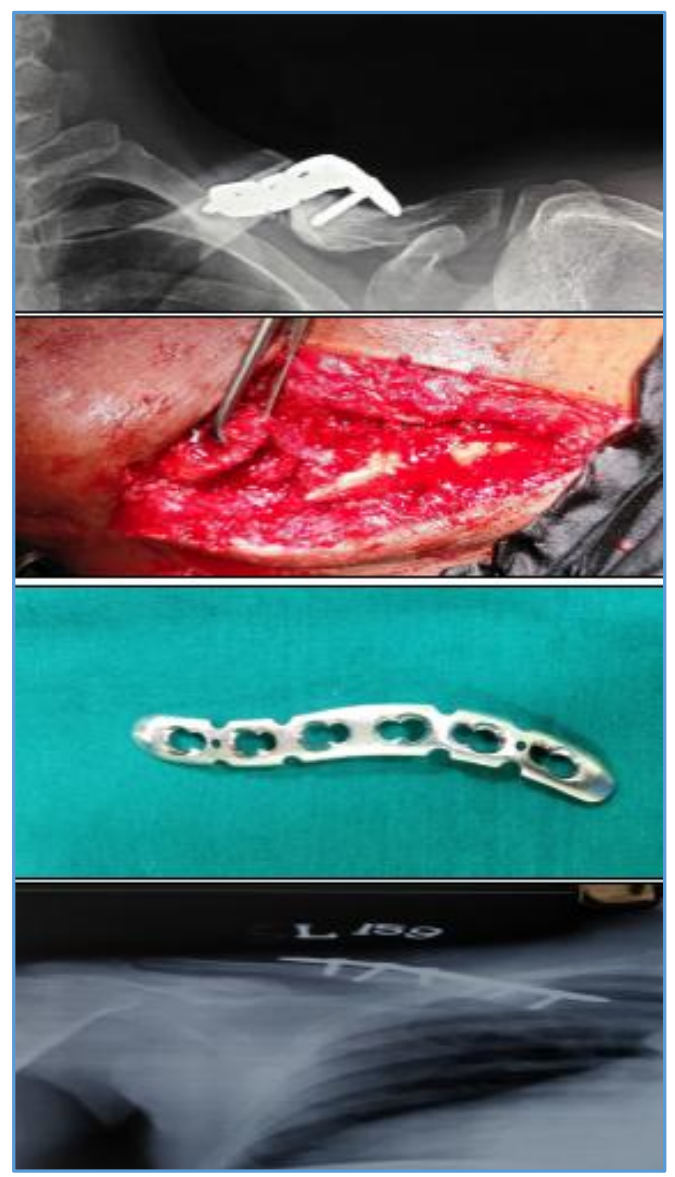

Figure (4) a. X-ray showing Implant Failure with NonUnion; b. Intraoperative Image confirming Non-Union; c. Image showing Bent Plate; d. Postop Image after Revision Surgery

\section{DISCUSSION}

Clavicle fracture is one of the fractures treated mostly conservatively and has provided good results. Recent studies have shown that rate of mal-union and non-union is more in fractures treated by conservative methods.[14,15] So recent trends indicate fixation of clavicle fracture by surgical means in order to achieve rapid union, decreased complications and early return to work.

Goal of surgical treatment is the anatomic reduction with reconstruction of clavicular length and alignment of the shoulder girdle. ${ }^{16}$ Among various methods of operative treatment of displaced midshaft clavicular fractures, plate osteosynthesis is still the standard method providing consistent results and good functional outcome. ${ }^{17}$

In our study, there were 22 male patients and 5 female patients. This is comparable to other studies of Elidrissi et al,18 where 32 males and 2 females were operated and Dhoju et al who included 16 male and 4 female patients.

In our study, right side clavicle fracture occurred in $77 \%$ of the cases. This is similar to study by Elidrissi et al, ${ }^{18}$ which signifies dominant hand is involved more.

RTA was the most common mode of fracture followed by accidental fall and sports injury in this study. Similar pattern was seen in studies by Bosnan et $\mathrm{al}^{19}$ and Cho et al. ${ }^{20}$

In our study, $70 \%$ patients were classified as Robinson type $2 \mathrm{~B} 1$ and rest (30\%) as $2 \mathrm{~B} 2$. Bosnan et al ${ }^{19}$ and Cho et $\mathrm{al}^{20}$ also showed similar percentages in their study.

The average time of fracture union in our study was 9.4 weeks. It is comparable to other studies like Gohiya et al,12 Kumar et al and Elidrissi et al,18 which shows union at 8.68 weeks, 9.2 weeks and 14 weeks respectively.

The functional outcome evaluated according to modified Constant-Murley score showed excellent functional results in $81 \%$ cases, good results in $13.8 \%$ cases and poor score in $3.2 \%$ cases. Mean Constant-Murley score was 92 with a range of 54 - 100. One case went into non-union followed by implant failure due to bent plate. Patient had started early weight bearing and full abduction against advice which could be the cause for the same. In this case implant was removed followed by plate fixation after 6 months and fracture united thereafter. In minor post-operative complications, there were 3 cases of hypertrophic scar and 2 cases of incisional numbness. No case of infection was noted. In a study conducted by Zlowodski et al $^{9}$ complication rates after plate fixation in displaced acute midshaft clavicle fractures were non-union in $2.2 \%$ cases. Schiffer et al ${ }^{21}$ also displayed implant failure and refracture after implant removal in $10 \%$ cases. This shows that results of our study group was in concordance to other studies.

\begin{tabular}{|c|c|c|}
\hline Study & Implant Failure & Malunion/Non-Union \\
\hline Elidrissi et al 18 & Nil & Nil \\
\hline Olivier et al ${ }^{22}$ & Nil & Nil \\
\hline Dhoju et al 23 & Nil & Nil \\
\hline Zlowodski et al $^{9}$ & Nil & $2.2 \%$ \\
\hline Natham et al24 & $3 \%$ & $20 \%$ \\
\hline Our Study & $3 \%$ & $3 \%$ \\
\hline
\end{tabular}

In our study anatomical locking LCP was used in 19 cases, while reconstruction plates were used in 8 cases. Reconstruction plates are easy to use and better adapted to clavicle by giving them required shapes, but biomechanical strength is relatively less for these plates. Whereas, 
anatomical locking LCP are more resistant against torsional and twisting forces providing a more stable construct. There were no significant differences at the time of union, but patients with anatomical LCP were able to return to work earlier than reconstruction plate patients. One case of implant failure was seen in anatomical LCP group, but this was attributed to early weight bearing and return to work than fixation failure. In a study by Eden et $\mathrm{al}^{25}$ comparing biomechanical strength between reconstruction plate and LCP it was found that LCP provides better biomechanical stability than reconstruction plates.

\section{CONCLUSION}

Open reduction and internal fixation of acute displaced midshaft clavicular fractures have given excellent functional outcome, fracture union, decreased complications and early return to work with overall satisfaction of study groups. One case went into implant failure followed by non-union due to early weight bearing and full range of motion of shoulder stressing the need for rest and guarded abduction in early stages post-operatively. There was no significant difference between fracture union between reconstruction plates and locking LCP, but cases treated with anatomical locking LCP were able to return to work earlier than reconstruction group. Limitation of our study is the small sample size and use of only one method of fracture fixation.

\section{REFERENCES}

[1] Keener JD, Dahners LE. Percutaneous pinning of displaced midshaft clavicle fractures. Techniques Shoulder \& Elbow Surgery 2006;7(4):175-81.

[2] Postacchini F, Gumina S, De Santis P, et al. Epidemiology of clavicle fractures. J Shoulder Elbow Surg 2002;11(5):452-6.

[3] Robinson CM. Fractures of the clavicle in the adult. Epidemiology and classification. J Bone Joint Surg (Br) 1998;80(3):476-84.

[4] Preston CF, Egol KA. Midshaft clavicle fractures in adults. Bull NYU Hosp Jt Dis 2009;67(1):52-7.

[5] Singh R, Rambani R, Kanakaris N, et al. A 2-year experience, management and outcome of 200 clavicle fractures. Injury 2012;43(2):159-63.

[6] Rowe CR. An atlas of anatomy and treatment of midclavicular fractures. Clin Orthop Relat Res 1968;58:29-42.

[7] Khan LAK, Bradnock TJ, Scott C, et al. Fractures of the clavicle. J Bone Joint Surg Am 2009;91(2):447-60.

[8] Hill JM, McGuire MH, Crosby LA. Closed treatment of displaced middle-third fractures of the clavicle gives poor results. J bone Joint Surg Br 1997;79(4):537-9.

[9] Zlowodski M, Zelle BA, Cole PA, et al. Treatment of acute midshaft clavicle fractures: systematic review of 2144 fractures: on behalf of the Evidence based Orthopedic Trauma Working group. J Orthop Trauma 2005;19(7):504-7.

[10] McKee RC, Whelan DB, Schemitsch EH, et al. Operative versus non-operative care of displaced midshaft clavicular fractures: a Meta-analysis of randomized clinical trials. J Bone Joint Surg Am 2012;94(8):67584.

[11] Altamimi SA, McKee MD, Canadian Orthopedic Society. Non-operative treatment compared with plate fixation of displaced mid clavicular fractures. Surgical technique. J Bone Joint Surg Am 2008;90 (Suppl 2 Pt 1):1-8.

[12] Gohiya A, Singh BS, Sharma P, et al. Impact of plate osteosynthesis on functional outcome in displaced midclaviclar fractures: a prospective observational study. Int J Med Res Rev 2015;3(4)366-71.

[13] Constant CR, Murley AH. A Clinical method of functional assessment of shoulder. Clin Ortop Relat Res 1987;(214):160-4.

[14] Kale SY, Chaudhari PL, Dhar SB, et al. A comparative study of the conservative and operative management of midshaft clavicle fracture based on functional outcome and post-operative complications. International Journal of Contemporary Medical Research 2016;3(10):2819-23.

[15] Naveen BM, Joshi GR, Harikrishnan B. Management of mid-shaft clavicular fractures: comparison between non-operative treatment and plate fixation in 60 patients. Strategies Trauma Limb Reconstr 2017;12(1):11-8.

[16] Jiang H. Qu W. Operative treatment of clavicle midshaft fractures using a locking compression plate: comparison between mini-invasive plate osteosynthesis (MIPPO) technique and conventional open reduction. Orthopaedics \& Traumatology Surgery and Research 2012;98(6):666-71.

[17] Smekal V, Oberladstaetter J, Struve P, et al. Shaft fractures of the clavicle: current concepts. Arch Orthop Trauma Surg 2009;129(6):807-15.

[18] Mohammed E, Mahadane H, Mechchat A, et al. Functional outcome of midclavicular fracture fixation utilising a reconstruction plate. Malays Orthop J 2013;7(3):6-9.

[19] Bostman O, Manninen M, Pihlajamaki H. Complications of plate fixation in fresh displaced midclavicular fracture. J Trauma 1997;43(5):778-83.

[20] Chul-Hyun C, Kwang-Soon S, Byung-Woo M, et al. Operative treatment of clavicle midshaft fractures: comparison between reconstruction plate and reconstruction locking compression plate. Clin Orthop Surg 2010;2(3):154-9.

[21] Schiffer G, Faymonville C, Skouras E, et al. Midclavicular fracture: not just a trivial injury: current treatment options. Dtsch Arztebl Int 2010;107(41):711-7.

[22] Verborgt 0, Pittoors K, Van Glabbeek F, et al. Plate fixation of middle-third fractures of the clavicle in the semi-professional athlete. Acta Orthop Belg 2005;71(1):17-21.

[23] Dhoju D, Shrestha D, Parajuli NP, et al. Operative fixation of displaced middle third clavicle (Edinburg Type 2) fracture with superior reconstruction plate osteosynthesis. Kathmandu Univ Med J 2011;9(36):286-90.

[24] Formaini N, Taylor BC, Backes J, et al. Superior versus anteroinferior plating of clavicle fractures. Orthopedics 2013;36(7); e898-904.

[25] Eden L, Doht S, Frey SP, et al. Biomechanical comparison of the locking compression superior anterior clavicle plate with seven and ten hole reconstruction plates in midshaft clavicle fracture stabilisation. Int Orthop 2012;36(12):2537-43. 